\title{
When Do Prices Matter Most? Rice, Wheat, and Corn Supply Response in China
}

\author{
Jan Brockhaus, Jikun Huang, Jiliang Hu, Matthias Kalkuhl, \\ Joachim von Braun, and Guolei Yang
}

\subsection{Introduction}

Unexpected high and volatile food prices during the 2007-2008 world food crisis and thereafter have reemphasized the question of how countries can protect themselves from supply shortages. In view of the various trade restrictions imposed by some major exporting countries, governments tend once again to focus more on self-sufficiency and food storage. Additionally, emerging economies like China aim at increasing their yields. This is because the possibilities of expanding agricultural land are limited, while population, total grain demand, and meat consumption are rising.

The primary purposes of analyzing the supply response are threefold in this chapter. First, this work aims to identify the different factors that can affect production, such as market prices, biophysical conditions, and infrastructure. The second objective is to analyze the differences in the effects of these factors on the different crops. The third aim is to evaluate how the predictive power of prices evolves over time and therefore to understand when farmers react most strongly to prices. Hence, a clear understanding of the farmers' planting and production behavior is needed.

J. Brockhaus $(\bowtie) \cdot$ M. Kalkuhl $\bullet$ J. von Braun

Center for Development Research (ZEF), University of Bonn, Walter-Flex-Str. 3, 53113 Bonn,

Germany

e-mail: jan.brockhaus@uni-bonn.de

J. Huang $\bullet \mathrm{J}$. Hu $\bullet \mathrm{G}$. Yang

Center for Chinese Agricultural Policy, Chinese Academy of Sciences, Institute of Geographic Sciences and Natural Resources Research, Jia 11 Datun Road, Anwai, Beijing 100101, China 
In the context of empirical estimations, farmers' decision-making is generally modeled as a two-step process (Colman 1983): First, farmers choose the crop type based on past weather conditions and decide their cropping area based on the prices they expect to receive several months later. Second, after planting, they change their farmland management measures according to market prices and weather condition to achieve a high yield. We focus on the production response of winter wheat, indica rice, and corn as these crops are the main staple foods in China. China is the biggest producer of rice and wheat and one of the biggest producers of corn. The results of the research can also be used as the basis for a short-term forecasting tool for monitoring Chinese food security or as part of a worldwide food availability monitoring tool. However, forecasting would require timely availability of data, which usually is not possible for data from the Chinese Agricultural Yearbooks.

In China, early works in this field have focused on the roles of price and marketing reforms in agricultural production (e.g. Lin 1991). Empirical studies have found a positive impact of price changes on output during the first years of reform (Lin 1992; Huang and Rozelle 1996). Lin (1992) found that $15 \%$ of output growth in 1978-1984 came from the rise in relative prices. Huang and Rozelle (1996) showed about $10 \%$ of rice output growth between 1978 and 1984 was caused by price effects. The gains have also resulted from increased allocative efficiency through market liberalization since the early 1990s. For example, de Brauw et al. (2004) showed that increasing marketization had a positive effect on crop allocation and productivity. The recent works have paid more attention to the impacts of subsidizing agriculture after China shifted its agricultural policy from taxing farming households to providing them with subsidies in 2004. While these subsidies are given to all producers and are very high, even higher than in the USA and the EU on a per unit area basis in 2012, they are quite low on a per household or per farm basis as farms in China are mostly of small scale (Huang et al. 2013). Except for subsidies for machinery, which influenced the purchase of machineries, most other subsidies for grain, input, and seed were found not to influence farmers' area allocation decisions (Huang et al. 2011). This finding provides the rationale behind not explicitly including subsidies in this study. Increased grain outputs in the later years were partly attributed to land reallocation to grain production (Yu and Jensen 2010). With the help of a dynamic panel approach, acreage and yield responses to output prices were analyzed in a case study for Henan (Yu et al. 2011). Both area and yield were found to be price-responsive. However, evidence from other provinces is missing, and the effects of high temperatures have not been addressed. This chapter focuses on both of these issues. Furthermore, the role of prices at different points in time is at the heart of this analysis. At the global level, price volatility and therefore price risks were found to reduce the supply response (Haile et al. 2016). However, as prices are comparably stable in China, price volatility was not considered as an important factor in this study.

In the face of global warming, interest in its impacts on agriculture is increasing. The impacts of climate change are expected to be huge and have already been partly documented. The general findings include an expected decline of crop yields in China, as in other developing countries (Tao et al. 2006). By employing farm- 
level data and the Ricardian method, the average impact of higher temperatures was found to be negative, whereas the average impact of more rainfall was found to be positive (Wang et al. 2009). Overall, weather conditions, market prices, and infrastructures can be seen as the three most important conditions for agriculture production. This study makes an important contribution to evaluating how such weather-related variables, especially high temperatures, affect the production of the considered crops at the province level. Furthermore, to our knowledge, this is the first study which addresses the production response to prices at different periods in time in order to analyze the farmers' price expectation formation process.

The next four sections present the data, methods, results, and conclusions, respectively.

\subsection{Data Description and Usage}

Data on acreage, production, output market prices, procurement prices, fertilizer prices, rainfall, consumer price index (CPI), irrigated area, temperatures, sunshine, effective irrigated area, and prices of competing crops were collected from the Chinese agricultural and statistical yearbooks from 1996 to 2012. Province-level data was used whenever possible, but whenever such data was scarce, nationallevel data was used instead. Own crop prices were deflated by the CPI; other prices were deflated by the own crop price, resulting in relative prices to take into account any possible correlation. Table 18.1 provides an overview of the aggregation level, frequency, and transformations of the data. The summary statistics of the variables are presented in Table 18.2 for the individual crops.

A panel data set was created for each crop, whereby the province-wise production of a crop was used as the dependent variable to be explained by the other variables. The provincial production data, collected from the National Bureau of Statistics of China, was collected from 1995 to 2012 and includes information on 20 provinces planting winter wheat, 29 provinces planting corn, 13 provinces planting early and late indica rice, and 15 provinces planting middle indica rice. For indica rice, data from the early, middle, and (double) late seasons were pooled together to get more observations and hence ensuring that the number of observations did not fall below 249. However, this came at the cost of not being able to detect any heterogeneity in the response which cannot be captured by the fixed effects.

The planting season and complementing and substituting crops may differ slightly among the different provinces. For winter wheat, the planting season is from September to October, and its harvesting takes place in the late April or May of the following year. The main substitute is rapeseed, followed by cotton, while corn is a complementing crop. Corn is mainly planted from April to June and harvested between August and October. The main substitutes are soybean and cotton, and the main complementing crops are wheat and rapeseed. Based on the farmers' production behavior, we focused on input and output prices, weather conditions, and infrastructure. For crop prices, monthly wholesale prices were used. This is because wholesale prices were more easily available than farm gate prices and also 
Table 18.1 Overview of the data used for the regression analysis

\begin{tabular}{|c|c|c|c|c|}
\hline Data & China ... yearbook & Scale & Frequency & Transformation \\
\hline Production & Rural statistic & Province & Yearly & Logged \\
\hline CPI & Statistical & Province & Monthly & $\begin{array}{l}\text { Continuous CPI build } \\
\text { from yearly changes }\end{array}$ \\
\hline Total farm crop area & Rural statistic & Province & Yearly & - \\
\hline Irrigated area & Water conservancy & Province & Yearly & $\begin{array}{l}\text { Divided by total farm } \\
\text { crop area and logged }\end{array}$ \\
\hline Nonirrigated area & - & Province & Yearly & $\begin{array}{l}\log (1 \text {-irrigated area/total } \\
\text { farm crop area })\end{array}$ \\
\hline Wholesale prices & Grain & National & Monthly & $\begin{array}{l}\text { Divided by continuous } \\
\text { CPI and logged (for } \\
\text { competing crop prices: } \\
\text { divided by own crop } \\
\text { price) }\end{array}$ \\
\hline Fertilizer prices & Price & National & Monthly & $\begin{array}{l}\text { Divided by wholesale } \\
\text { price and logged }\end{array}$ \\
\hline Rainfall & Water conservancy & Province & Monthly & Logged \\
\hline Hours of sunshine & 1 & Province & Monthly & Logged \\
\hline Lowest temperature & 1 & Province & Monthly & - \\
\hline Average temperature & 1 & Province & Monthly & - \\
\hline Highest temperature & 1 & Province & Monthly & - \\
\hline Area affected by drought & Water conservancy & Province & Yearly & $\begin{array}{l}\text { Divided by total farm } \\
\text { crop area and logged }\end{array}$ \\
\hline
\end{tabular}

Note: The second column shows the source, i.e., from which of China's yearbooks the data is taken. 1 means that it is not taken from any yearbook but from the National Meteorological Information Center of China

because of the high transmission from wholesale to farm gate prices, as reported in the literature (Liu et al. 2012).

As land and labor are limited, planting behavior can be affected by the price of competing crops. Fertilizer prices were chosen as the main input market price. Wages, obtained from Bloomberg, were also included, but their time series is short and as a result so is the number of observations. Due to this and the fact that they turned out to be insignificant, they were not reported in this chapter but are available upon request. The agricultural production system is sensitive to weather effects, and there are very few measures available to farmers to compensate for weather effects. Therefore, weather conditions, collected from the National Meteorological Information Center of China, were a very important independent variable in this analysis. The percentage share of cultivated area under irrigation can also be seen as a measure of infrastructure and technology. Missing values for this variable, but not for any other variables, were imputed. Irrigation also allows farmers to compensate for insufficient rainfall and partly even droughts. As irrigation is typically used in combination with the application of chemical fertilizers, it represents a higher standard of agricultural infrastructure. However, irrigation relates to the cultivated land area under irrigation and hence is not crop specific. As a result, only very 
Table 18.2 Summary statistics of the data from all provinces

\begin{tabular}{|c|c|c|c|c|c|}
\hline & Obs & Mean & SD & Min & Max \\
\hline \multicolumn{6}{|l|}{ Corn } \\
\hline Production (1000 tons) & 552 & 458.7 & 549.5 & 0.9 & 2675.8 \\
\hline June WSP (CNY/kg) & 463 & 1.4 & 0.4 & 0.9 & 2.3 \\
\hline Irrigation (1000 ha) & 552 & 1813.9 & 1385.8 & 144.2 & 5205.6 \\
\hline Rainfall @ growing (cm) & 534 & 14.1 & 6.8 & 1.5 & 40.4 \\
\hline Average temp @ growing $\left({ }^{\circ} \mathrm{C}\right)$ & 534 & 24.9 & 3.3 & 13.2 & 30.7 \\
\hline Drought area (1000 ha) & 495 & 448.1 & 544.2 & 1.0 & 3133.0 \\
\hline Fertilizer price $(\mathrm{CNY} / \mathrm{kg})$ & 492 & 1916.4 & 672.6 & 1186.0 & 3140.0 \\
\hline \multicolumn{6}{|l|}{ Winter wheat } \\
\hline Production (1000 tons) & 360 & 464.3 & 686.8 & 0.2 & 3177.4 \\
\hline March WSP (CNY/kg) & 301 & 1.5 & 0.4 & 1.0 & 2.2 \\
\hline April's sunshine hours & 360 & 5.6 & 1.8 & 1.7 & 9.4 \\
\hline Irrigation (1000 ha) & 360 & 2041.9 & 1466.8 & 173.6 & 5205.6 \\
\hline Rainfall @ growing (cm) & 360 & 6.0 & 4.8 & 0.2 & 22.4 \\
\hline High temp @ flowering $\left({ }^{\circ} \mathrm{C}\right)$ & 360 & 26.0 & 4.1 & 16.6 & 37.3 \\
\hline Rainfall @ planting (cm) & 360 & 2.9 & 1.6 & 0.1 & 11.7 \\
\hline Drought area (1000 ha) & 321 & 399.5 & 482.9 & 1.0 & 2573.0 \\
\hline Fertilizer price $(\mathrm{CNY} / \mathrm{kg})$ & 320 & 1897.8 & 665.3 & 1184.0 & 3000.0 \\
\hline \multicolumn{6}{|l|}{ Indica rice } \\
\hline Production (1000 tons) & 707 & 406.1 & 433.0 & 0.0 & 2161.1 \\
\hline WSP @ planting (CNY/kg) & 594 & 1.5 & 0.4 & 0.9 & 2.5 \\
\hline Sunshine hours@ planting & 707 & 5.4 & 1.4 & 2.1 & 10.4 \\
\hline Irrigation (1000 ha) & 707 & 1751.3 & 985.5 & 169.9 & 3929.7 \\
\hline Rainfall @ growing $(\mathrm{cm})$ & 707 & 11.4 & 4.3 & 2.6 & 26.2 \\
\hline Rainfall @ planting (cm) & 707 & 3.8 & 2.6 & 0.1 & 19.5 \\
\hline High temp @ growing $\left({ }^{\circ} \mathrm{C}\right)$ & 707 & 33.7 & 2.0 & 27.2 & 39.7 \\
\hline Drought area (1000 ha) & 639 & 292.9 & 361.0 & 1.0 & 2250.0 \\
\hline Fertilizer price $(\mathrm{CNY} / \mathrm{kg})$ & 632 & 1867.1 & 668.0 & 1126.0 & 3340.0 \\
\hline
\end{tabular}

Note: Data which is only available on a national basis has been copied for all provinces and therefore is shown to have more observations than it actually has on the national level. Data is only reported if the value for production for that crop, year, and province is available. Unless the month is indicated, the @ is used to specify time periods

limited conclusions can be drawn about how irrigation affects production. This is discussed further in Sect. 18.4 and also applies to the drought area, which is also not crop specific.

As some of the weather data has a high level of autocorrelation, it is not possible to consider every month in the econometric analysis. Therefore, only the most important month is included, except for rainfall, in which case the sum of the most important months is calculated. The hypotheses to test in this chapter are as follows: (1) A positive response to own output prices, and a negative response to competing crop prices as well as fertilizer prices, at least if the crop has a higher fertilizer 
requirement than competing crops; (2) own output prices matter most in the time period from shortly before to a few month after planting, during which farmers make their decisions on areas and yields; (3) droughts and insufficient rainfall have a negative effect on production; (4) irrigation has a positive impact and can reduce the negative impact of insufficient rainfall or high temperatures.

This approach has some limitations. The biggest limitation might be the aggregation level of data. Some price data were only available at a national level, but as price transmission within China is high (Huang and Rozelle 2006), this might not be a concern. For the biophysical variables, even though they were available at the provincial level, this aggregation might be more problematic as rainfall, hours of sunshine, and temperatures may vary in different parts of the same province. Therefore, the influence of these biophysical variables is likely to be underestimated due to this high level of aggregation. Furthermore, important variables may not be considered which could be an issue if they fluctuate a lot in the short term. If they mostly consist of a long-term trend instead, then they will be captured by orthogonal deviations and lagged production and, as a result, will not cause any problems.

\subsection{Methodology}

Strictly speaking, a farmer's decision-making process consist of two steps: the area decision and the yield decision (Colman 1983). The considered determinants are mostly the same but may differ slightly as, for example, competing crop prices are not that important after the area decision was made. However, they still may be important because they may affect how farmers allocate their inputs such as fertilizers, pesticides, and water and other variables. On the other hand, not all variables which influence yields also matter when allocating the area. Unexpected rainfall shocks (or price shocks) after planting cannot be anticipated and therefore cannot affect the area decision. However, these shocks may affect a farmer's fertilizer application and therefore yield. Therefore, modeling production is a combination of the area and yield processes and can only be investigated by considering the sum of both effects. Nevertheless, it is important to see the combined effects as we are interested in the total production volume and want to know which variables have an influence and how the variables influence. Another reason to look at the combined effect on production is that statistical issues arise when looking at area and yield separately. This is because area and yield influence one another, and therefore this additional endogeneity has to be dealt with. For example, area allocation decisions may affect yields in two different ways: High prices could cause farmers to favor large planting areas, which should increase the expected yields, whereas planting area expansion may negatively influence yields if the additional crop areas are located on less-productive lands.

The Arellano-Bond difference GMM and system GMM estimators (Holtz-Eakin et al. 1988; Arellano and Bond 1991; Arellano and Bover 1995; Blundell and Bond 1998) were used for a number of reasons. First, the time period was rather short, usually around 14 years, while the number of observations per time period was 
comparatively large: 20 for wheat, over 29 for corn, and around 40 for rice. The difference GMM and system GMM estimators control for such dynamic panel bias. Second, the production response is a dynamic process, i.e., current realizations depend on past ones. Third, fixed effects allow for heterogeneity across groups, namely provinces. Last, idiosyncratic disturbances may have individual-specific patterns of heteroskedasticity.

For all three crops, four different specifications are shown in the tables in Sect. 18.4, with the first three presenting different control variables for the difference GMM estimator and the fourth illustrating the results for the last specification using the system GMM estimator for comparison and robustness checks. While including more variables allowed more factors to be controlled for, it also decreased the degrees of freedom, the significance of variables which are correlated and most importantly the number of observations (because many variables could only be obtained for a limited number of years). Comparing the different specifications and comparing the difference and system GMM results provide a further consistency check. In general, we think that the difference GMM estimator is more appropriate as it cannot be ruled out that the first differences of the instrument variables are uncorrelated with the group fixed effects. Our findings support this hypothesis, as will be shown in the next chapter. The Windmeijer finite-sample correction for standard errors was used (Windmeijer 2005). We used the xtabond2 command in Stata, which was written by David Roodman, and followed the application guidelines in his accompanying paper (Roodman 2009). Instead of first differencing, forward orthogonal deviations were used (Arellano and Bover 1995; Roodman 2009), i.e., the average of all available future observations was subtracted. This procedure removes fixed effects, just like differencing, but because lagged observations are not used, these remain orthogonal to the transformed errors. This way, the number of observations will not be reduced by gaps in the dataset. As suggested, time dummies for all years were included in all model specifications (ibid).

For proper usage of the GMM techniques, a number of tests need to be run to check the consistency of the estimations (ibid.; Efendic et al. 2009). The joint significance of the variables was evaluated with an $F$-test, the $p$-value of which we expected to be clearly below 0.1 (ibid.). While the first lagged residuals are expected to be correlated, the twice lagged residuals must not (Arellano and Bond 1991). Considering the null hypotheses, this means the $p$-value of the AR1 test in the result tables was expected to be smaller than 0.1, while the $p$-value for the AR2 test should be higher than 0.1 (for significance at the $10 \%$-level). Furthermore, the Hansen- $J$ test allows checking if the model specification and all over-identifying restrictions are correct (Baum 2006). It is suggested that the $p$-value should be above 0.25 but at the same time should not perfectly match 1 for this test (Roodman 2009). The difference-in-Hansen test was used to investigate the exogeneity of instruments. The null hypothesis is that they are exogenous. Hence, the respective $p$-values have to be above 0.1 in order to not reject the null hypothesis. The number of instruments was chosen to provide robust test statistics. There are no clear rules about the appropriate number of instruments. However, the number of instruments should always clearly be lower than the number of observations, which is the case for all our specifications. 
Furthermore, the coefficient of the lagged endogenous variable (production in our case) should be less than one to obtain a steady state behavior (Roodman 2009), which is the case in all of the presented models. Finally, the validity of the estimates can be verified by examining if the coefficient of the lagged dependent variable is larger than the one obtained by a fixed effects model and smaller than one obtained by using OLS (Bond 2002). This was the case for all specifications and the FE and OLS estimates of the lagged dependent variables are reported in the tables.

All the test statistics were fulfilled in all specifications except for two instances: (1) the first specification for winter wheat, which failed to reject the second order autocorrelation at the $10 \%$ level but nevertheless did so at the $5 \%$ level; and (2) the first specification for indica rice, which failed to reject the Hansen- $J$ test and the difference-in-Hansen test.

Apart from evaluating the production response using the price at a predetermined point in time, this work aims at analyzing how production responds to prices at different points in time. Therefore, the regressions were conducted with prices at different months before and after planting, from 20 months before up to 20 months after planting, and how this changes the results is graphically illustrated. For this analysis, the second specification is used for all crops as this specification provides the maximum number of observations while fulfilling all test criteria and while including the most important variables. This procedure allowed us to analyze how farmers build their price expectations, in particular whether they used previous year's prices around planting or harvesting time or if they used the latest prices which, under the assumption of efficient markets, incorporate all available information about supply and demand.

For indica rice, data for the three different seasons were pooled together. Hence, there is no fixed planting month, but the appropriate planting month was chosen depending on the season instead. All the other variables were similarly chosen relative to the month of planting for that season. This means, for example, that the planting time price is April for early indica, May for middle indica, and July for late indica rice. Similarly, rainfall during the growing season refers to April and May for early indica, May and June for middle indica, and July and August for late indica rice.

All variables were logged, and therefore the effects can be interpreted as elasticities. The only exception are temperatures, which also exhibited negative values and are more intuitive to interpret in their non-logged form.

\subsection{Results}

\subsubsection{Basic Regression Results}

The results for the production of corn are shown in Table 18.3, for winter wheat in Table 18.4, and for indica rice in Table 18.5. The first row always shows the lagged production. Wholesale prices are denoted by WSP followed by the month or relative time period. The latter are always denoted by the @ symbol and refer to 
Table 18.3 Results for corn production response

\begin{tabular}{|c|c|c|c|c|}
\hline & $(1)$ & $(2)$ & (3) & (4) \\
\hline L. Production & $\begin{array}{l}.807 * * * \\
(.166)\end{array}$ & $\begin{array}{l}.772 * * * \\
(.143)\end{array}$ & $\begin{array}{l}.902 * * * \\
(.139)\end{array}$ & $\begin{array}{l}.956 * * * \\
(.034)\end{array}$ \\
\hline WSP June & \begin{tabular}{|l}
$.296 * * *$ \\
$(.077)$
\end{tabular} & $\begin{array}{l}.291 * * * \\
(.055)\end{array}$ & $\begin{array}{l}.226 * * * \\
(.065)\end{array}$ & $\begin{array}{l}.177 * * * \\
(.05)\end{array}$ \\
\hline Irrigated & $\begin{array}{l}-.115 \\
(.131)\end{array}$ & $\begin{array}{l}20.1 * * \\
(8.12) \\
\end{array}$ & $\begin{array}{l}16.8^{* *} \\
(8.07)\end{array}$ & $\begin{array}{l}1.61 \\
(6.65) \\
\end{array}$ \\
\hline Rain@growing & $\begin{array}{l}-.059 \\
(.063)\end{array}$ & $\begin{array}{l}-.013 \\
(.06)\end{array}$ & $\begin{array}{l}-.076 \\
(.08)\end{array}$ & $\begin{array}{l}-7.4 \mathrm{e}-03 \\
(.033)\end{array}$ \\
\hline A-Temp@growing & $\begin{array}{l}-.029 * \\
(.015)\end{array}$ & $\begin{array}{l}-.095 * * * \\
(.026)\end{array}$ & $\begin{array}{l}-.058^{*} \\
(.029)\end{array}$ & $\begin{array}{l}-.014 \\
(.024)\end{array}$ \\
\hline Drought area & $\begin{array}{l}-.032 * * * \\
(8.6 \mathrm{e}-03)\end{array}$ & $\begin{array}{l}-.033 * * * \\
(9.1 \mathrm{e}-03)\end{array}$ & $\begin{array}{l}-.035^{* * * *} \\
(.01)\end{array}$ & $\begin{array}{l}-.014 \\
(.013)\end{array}$ \\
\hline Nonirrigated X rain @ growing & & $\begin{array}{l}.077 * \\
(.045)\end{array}$ & $\begin{array}{l}.071 * \\
(.037)\end{array}$ & $\begin{array}{l}.066 * * * \\
(.021)\end{array}$ \\
\hline Irrigated X A-temp @ growing & & $\begin{array}{l}-.067 * * \\
(.027)\end{array}$ & $\begin{array}{l}-.052 * \\
(.027)\end{array}$ & $\begin{array}{l}-5.3 e-04 \\
(.023)\end{array}$ \\
\hline Fertilizer@planting & & & $\begin{array}{l}-.203 * * \\
(.074)\end{array}$ & $\begin{array}{l}-.231 * * * \\
(.065)\end{array}$ \\
\hline Irrigated X fertilizer @ planting & & & $\begin{array}{l}-.182 * * \\
(.068)\end{array}$ & $\begin{array}{l}-.191 * * * \\
(.058)\end{array}$ \\
\hline Substitute @ planting & & & $\begin{array}{l}.018 \\
(.027)\end{array}$ & $\begin{array}{l}6.3 \mathrm{e}-03 \\
(.017)\end{array}$ \\
\hline Constant & & & & $\begin{array}{l}6.29 \\
(6.9) \\
\end{array}$ \\
\hline Estimator & Difference & Difference & Difference & System \\
\hline Groups & 29 & 29 & 29 & 29 \\
\hline Instruments & 27 & 29 & 28 & 30 \\
\hline$p: F$-test & $1.7 \mathrm{e}-19$ & $1.3 e-23$ & $1.1 \mathrm{e}-27$ & $4.0 \mathrm{e}-37$ \\
\hline$p: \mathrm{AR} 1$ & $1.5 \mathrm{e}-03$ & $1.1 \mathrm{e}-03$ & $9.9 \mathrm{e}-04$ & $3.2 \mathrm{e}-04$ \\
\hline$p: \mathrm{AR} 2$ & .919 & .685 & .949 & .581 \\
\hline$p:$ Hansen- $J$ & .291 & .326 & .286 & .535 \\
\hline$p$ :Diff-Hansen & .812 & .9 & .436 & 1 \\
\hline OLS & .988 & .991 & .985 & .985 \\
\hline FE & .741 & .683 & .747 & .747 \\
\hline Observations & 384 & 384 & 296 & 325 \\
\hline
\end{tabular}

Note: Standard errors in parentheses. WSP: wholesale price; $\mathrm{X}$ indicates interaction terms; A-temp: average temperature; specifications with different explanatory variables for the difference GMM estimator (1-3); for comparison and robustness checks, the results of the last specification are also shown for the system GMM estimator (4) $p<0.10, * * p<0.05, * * * p<0.01$ 
Table 18.4 Results for winter wheat production response

\begin{tabular}{|c|c|c|c|c|}
\hline & $(1)$ & $(2)$ & (3) & (4) \\
\hline L. Production & \begin{tabular}{|l}
$.951 * * *$ \\
$(.104)$
\end{tabular} & $\begin{array}{l}.951 * * * \\
(.11)\end{array}$ & $\begin{array}{l}.96 * * * \\
(.087)\end{array}$ & \begin{tabular}{|l}
$.964 * * *$ \\
$(.063)$
\end{tabular} \\
\hline WSP March & & $\begin{array}{l}.338 * * * \\
(.116)\end{array}$ & $\begin{array}{l}.292 * * \\
(.132)\end{array}$ & $\begin{array}{l}.255^{*} \\
(.143)\end{array}$ \\
\hline H-temp @ flowering & $\begin{array}{l}-.043 * * * \\
(9.6 \mathrm{e}-03)\end{array}$ & $\begin{array}{l}-.044 * * \\
(.019)\end{array}$ & $\begin{array}{l}.061 \\
(.123)\end{array}$ & $\begin{array}{l}-.037 \\
(.122)\end{array}$ \\
\hline Sun @ flowering & \begin{tabular}{|l}
.156 \\
$(.092)$
\end{tabular} & $\begin{array}{l}.081 \\
(.205)\end{array}$ & $\begin{array}{l}.124 \\
(.207)\end{array}$ & \begin{tabular}{|l}
.196 \\
$(.293)$
\end{tabular} \\
\hline Rain@planting & $\begin{array}{l}.054 * * \\
.021)\end{array}$ & $\begin{array}{l}.045 \\
(.026)\end{array}$ & $\begin{array}{l}.04 \\
(.042)\end{array}$ & \begin{tabular}{|l|}
.047 \\
$(.037)$
\end{tabular} \\
\hline Rain@growing & $\begin{array}{l}3.5 \mathrm{e}-04 \\
(.032)\end{array}$ & $\begin{array}{l}-.045 \\
(.037)\end{array}$ & $\begin{array}{l}-.143 \\
(.099)\end{array}$ & $\begin{array}{l}-.133 \\
(.091)\end{array}$ \\
\hline Irrigated & $\begin{array}{l}-.055 \\
(.483)\end{array}$ & $\begin{array}{l}-.344 \\
(.478)\end{array}$ & $\begin{array}{l}-31.9 \\
(37.2)\end{array}$ & $\begin{array}{l}-.093 \\
(26.4)\end{array}$ \\
\hline Drought area & $\begin{array}{l}-.037 * * \\
(.014)\end{array}$ & $\begin{array}{l}-.026 \\
(.016)\end{array}$ & $\begin{array}{l}-.034 \\
(.02)\end{array}$ & $\begin{array}{l}-.026^{*} \\
(.014)\end{array}$ \\
\hline Nonirrigated X rain@ growing & & & $\begin{array}{l}-.137 \\
(.135)\end{array}$ & $\begin{array}{l}-.177 \\
(.165)\end{array}$ \\
\hline Irrigated X H-temp @ flowering & & & $\begin{array}{l}.105 \\
(.125)\end{array}$ & $\begin{array}{l}-1.1 \mathrm{e}-03 \\
(.089)\end{array}$ \\
\hline Constant & & & & $\begin{array}{l}10.3 \\
(36)\end{array}$ \\
\hline Estimator & Difference & Difference & Difference & System \\
\hline Groups & 20 & 20 & 20 & 20 \\
\hline Instruments & 26 & 25 & 27 & 29 \\
\hline$p: F$-test & $1.4 \mathrm{e}-13$ & $2.0 \mathrm{e}-12$ & $2.0 \mathrm{e}-14$ & $1.8 \mathrm{e}-22$ \\
\hline$p: \mathrm{AR} 1$ & $8.8 \mathrm{e}-03$ & .019 & .012 & .016 \\
\hline$p: \mathrm{AR} 2$ & .053 & .185 & .173 & .241 \\
\hline$p:$ Hansen- $J$ & .595 & .463 & .805 & .744 \\
\hline$p$ :Diff-Hansen & .949 & .847 & 1 & 1 \\
\hline OLS & 1.01 & 1.02 & 1.02 & 1.02 \\
\hline FE & .865 & .855 & .863 & .863 \\
\hline Observations & 280 & 249 & 249 & 269 \\
\hline
\end{tabular}

Note: Standard errors in parentheses. WSP: wholesale price; $\mathrm{X}$ indicates interaction terms; H-temp: high temperature; specifications with different explanatory variables for the difference GMM estimator (1-3); for comparison and robustness checks, the results of the last specification are also shown for the system GMM estimator (4)

$p<0.10, * * p<0.05, * * * p<0.01$ 
Table 18.5 Results for indica rice production response

\begin{tabular}{|c|c|c|c|c|}
\hline & (1) & (2) & (3) & (4) \\
\hline L. Production & $\begin{array}{l}.913 * * * \\
(.07)\end{array}$ & $\begin{array}{l}.914 * * * \\
(.055)\end{array}$ & $\begin{array}{l}.778 * * * \\
(.112)\end{array}$ & $\begin{array}{l}.911 * * * \\
(.081)\end{array}$ \\
\hline WSP@ planting & $\begin{array}{l}.196 * * * \\
(.067)\end{array}$ & $\begin{array}{l}.181 * * * \\
(.054)\end{array}$ & $\begin{array}{l}.163 * * \\
(.061)\end{array}$ & $\begin{array}{l}.241 * * \\
(.094)\end{array}$ \\
\hline Rain@ growing & $\begin{array}{l}.053^{*} \\
(.027)\end{array}$ & $\begin{array}{l}.152 \\
(.139)\end{array}$ & $\begin{array}{l}.115 \\
(.178)\end{array}$ & $\begin{array}{l}.425 \\
(.284)\end{array}$ \\
\hline Sun @ growing & $\begin{array}{l}.174 * * * \\
(.061)\end{array}$ & $\begin{array}{l}.167 * * * \\
(.05)\end{array}$ & $\begin{array}{l}.142 * \\
(.074)\end{array}$ & $\begin{array}{l}.023 \\
(.117)\end{array}$ \\
\hline H-temp@ growing & $\begin{array}{l}-.024 * * \\
(.01)\end{array}$ & $\begin{array}{l}-.026 * * * \\
(8.5 \mathrm{e}-03)\end{array}$ & $\begin{array}{l}-.039 * * * \\
(.013)\end{array}$ & $\begin{array}{l}.019 \\
.03)\end{array}$ \\
\hline Irrigated & & $\begin{array}{l}.356 \\
(.521)\end{array}$ & $\begin{array}{l}.323 \\
(.674)\end{array}$ & $\begin{array}{l}1.06 \\
(.731)\end{array}$ \\
\hline Nonirrigated X rain @ growing & & \begin{tabular}{|l}
.294 \\
$(.287)$
\end{tabular} & $\begin{array}{l}.262 \\
(.346)\end{array}$ & $\begin{array}{l}.691 \\
(.495)\end{array}$ \\
\hline Drought area & & $\begin{array}{l}-4.9 \mathrm{e}-03 \\
(8.8 \mathrm{e}-03)\end{array}$ & $\begin{array}{l}-1.4 \mathrm{e}-03 \\
(8.0 \mathrm{e}-03)\end{array}$ & $\begin{array}{l}4.6 \mathrm{e}-03 \\
(.012)\end{array}$ \\
\hline Fertilizer@planting & & & $\begin{array}{l}.032 \\
(.078)\end{array}$ & $\begin{array}{l}-.048 \\
(.058)\end{array}$ \\
\hline Substitute@ planting & & & $\begin{array}{l}.018 \\
(.032)\end{array}$ & $\begin{array}{l}.04 \\
(.048)\end{array}$ \\
\hline Constant & & & & $\begin{array}{l}-4.51 \\
(9.08)\end{array}$ \\
\hline Estimator & Difference & Difference & Difference & System \\
\hline Groups & 41 & 39 & 39 & 39 \\
\hline Instruments & 20 & 23 & 22 & 24 \\
\hline$p: F$-test & $2.8 \mathrm{e}-16$ & $3.2 \mathrm{e}-20$ & $1.2 \mathrm{e}-15$ & $1.0 \mathrm{e}-22$ \\
\hline$p: A R 1$ & .073 & .098 & .118 & .096 \\
\hline$p: \mathrm{AR} 2$ & .174 & .171 & .142 & .138 \\
\hline$p:$ Hansen- $J$ & .153 & .341 & .409 & .24 \\
\hline$p:$ Diff-Hansen & .088 & .102 & .227 & .569 \\
\hline OLS & .997 & .998 & .994 & .994 \\
\hline $\mathrm{FE}$ & .727 & .722 & .551 & .551 \\
\hline Observations & 548 & 503 & 394 & 433 \\
\hline
\end{tabular}

Note: Standard errors in parentheses. WSP: wholesale price; $\mathrm{X}$ indicates interaction terms; H-temp: high temperature; specifications with different explanatory variables for the difference GMM estimator (1-3); for comparison and robustness checks, the results of the last specification are also shown for the system GMM estimator (4)

$p<0.10,{ }^{* *} p<0.05, * * * p<0.01$ 
the planting, growing, flowering, or harvesting season of the crop. Average and high temperatures are written as A-temp and $\mathrm{H}$-temp, respectively. Interaction terms are indicated by an X, while the prices of competing crops are presented as substitute. The bottom part of the tables shows which estimator was used; the test statistics; and the number of groups, instruments, and observations.

The results for corn, illustrated in Table 18.3, show that all specifications seem to be valid based on the provided test statistics. A significant amount of variation in production can be explained by the previous year's production (which also takes into account unobserved variables). The coefficient ranges from 0.772 to 0.956 and is significant at the $1 \%$ level in all specifications. The wholesale price in June turned out to be also always highly significant and had a major contribution, as evident in its elasticity of around 0.2 . This implies that a $1 \%$ increase in prices will lead to a $0.2 \%$ increase in production, which seems reasonable and is comparable to the results obtained by similar studies. The fraction of irrigated area is only significant in two specifications but has a huge impact in both. However, it is only significant for the difference GMM specifications that included the interaction terms, which could possibly be attributed to collinearity in these variables (their correlation coefficient is -0.79 for corn, -0.17 for wheat, and -0.46 for rice). In addition, the total effect of irrigation is the elasticity of irrigation plus the interaction term of irrigation with the average temperature. The interaction term takes the value of -20.69 at the sample mean for the second specification, resulting in a combined marginal effect of -0.59 . Despite corn needing rainfall during the growing season, the rainfall variable did not seem to have any significant effect on the corn production. However, corn needs little water compared to other staples and in particular vegetables. As mentioned in Sect. 18.2, the irrigation variable measures the total cultivated area under irrigation. This may not be a good proxy for the actual irrigated crop areas; in particular, it is not a measure of crop-specific irrigation. Furthermore, the quality of irrigation is not reflected in this variable. Moreover, considering rainfall variability and water availability, the quality of irrigation may change drastically over time. Therefore, the influence of irrigation can only be approximated, and thus it is unsurprising that no effect was found in many of the specifications (when compared with wheat and rice).

High average temperatures during the growing season, which is in mid-summer, have a small but significant negative impact. When interacted with the nonirrigated area (i.e., the fraction of the agricultural area which is not irrigated), we found that rainfall during the growing season became significant. As expected, rainfall had a positive influence on production, albeit a small one. When interacted with irrigation, high average temperatures are negative and significant for the difference GMM specification. This differs from our expectations but might be explained by the imprecise approximation of irrigation or by high temperatures offsetting the benefits of irrigation. As expected, the drought area had a significant and negative influence in all but the system GMM specifications. High fertilizer prices at planting time reduced the total production; again, this effect seems to be more pronounced in provinces with a high share of irrigated area. This may be attributed to the fact that levels of fertilizer application are usually much higher on irrigated areas, which 
may therefore be over-proportionally affected. Prices of competing crops turned out to be insignificant, despite testing various ways of including them in the analysis, such as using the province-specific main competing crop only or a weighted average of competing crops.

For winter wheat, presented in Table 18.4 , the previous year's production was again the most important driver and consistently significant at the $1 \%$ level. Wholesale prices in March had a similar positive and significant effect, as for corn. The elasticity is around 0.29 , even slightly higher than for corn. The first specification did not include any prices to ascertain if there are any changes when more observations are included. This is because the number of observations for winter wheat is relatively low compared with corn and rice. The amount of sunshine at flowering (around two months before harvesting) is insignificant. From the literature, wheat is expected to require much sunshine during this period (FAO 2015). Furthermore, much rain is needed during and shortly after planting as well as during flowering and yield formation (ibid.). The positive influence of rainfall during and after planting can be observed in the first specification only. Rainfall during the growing season and its interaction term with the nonirrigated area are always insignificant. This might be a result of data aggregation, as explained above. The irrigated area seems to have no effect, but this may be attributed to the poor approximation of irrigation, as explained above. The drought area has a significant negative impact in two specifications, again albeit with a very small effect. The expected negative effect of overly high temperatures during flowering time vanished once the interaction term with irrigation is included. Then, both terms became insignificant. Fertilizer prices and prices of competing crops had no significant effect but reduced the number of observations significantly. Therefore, they are not shown separately but are available upon request.

Similar to corn and wheat, lagged production was the most important driver of indica rice production, as illustrated in Table 18.5. The effect of the wholesale price is similar to the case of corn; it was always significant and had an effect size of around 0.2. Rain during the growing season, a large amount of which is required to flood rice paddy fields, was positive but only significant at the $10 \%$ level in one specification. But as explained before, this might be a result of aggregating rainfall data across the provincial level. The results did not change when we included squared rainfall. Even when interacted with the nonirrigated area, the rainfall stayed insignificant. The irrigated area itself is insignificant, which, as detailed before, might be attributed to the poor proxy used for irrigation. For sunshine, we found that a $1 \%$ increase in the number of hours of sunlight increased the production by around $0.16 \%$ in all the difference GMM specifications. Similarly, the damaging effect of overly high temperatures during the growing season can be observed in all difference GMM specifications. The drought area, fertilizer prices, and the prices of competing crops all turned out to be insignificant. The underlying reasons might be that the costs of switching crops from rice are relatively high and that rice needs a comparatively small amount of fertilizer per unit of output. 
Overall, our results were mostly comparable to other similar studies. In a noncrop specific analysis, Ghatak and Seale (2001) found that price elasticity was between 0.174 and 0.394 , which is similar to ours. Looking only at the national level, own price elasticities of 0.23 for rice, 0.052 for wheat, and 0.164 for corn have been reported (Haile et al. 2015). Our results for rice and corn were comparable, whereas we found a higher price response for wheat. For Henan, Yu et al. (2011) found no significant response for wheat but a surprisingly high elasticity of 0.737 for corn. However, according to the study, the elasticities of competing crop prices were also high and significant. They also reported that rainfall increased winter wheat production when considering the total effect on area and yield. For corn, they found that rainfall had no effect, which is consistent with our results if only the non-interacted rainfall is considered, as in the study by Yu et al.

\subsubsection{Impact of Prices on Production During the Marketing Year}

As explained in Sect. 18.3, one of the aims of this chapter is to analyze how production reacts to prices at different points in time. Therefore, the regressions with same specifications were run for prices at different months before and after the planting time. For all other variables, the values used remain the same as before. The results are depicted in Fig. 18.1 for corn, in Fig. 18.2 for winter wheat, and in

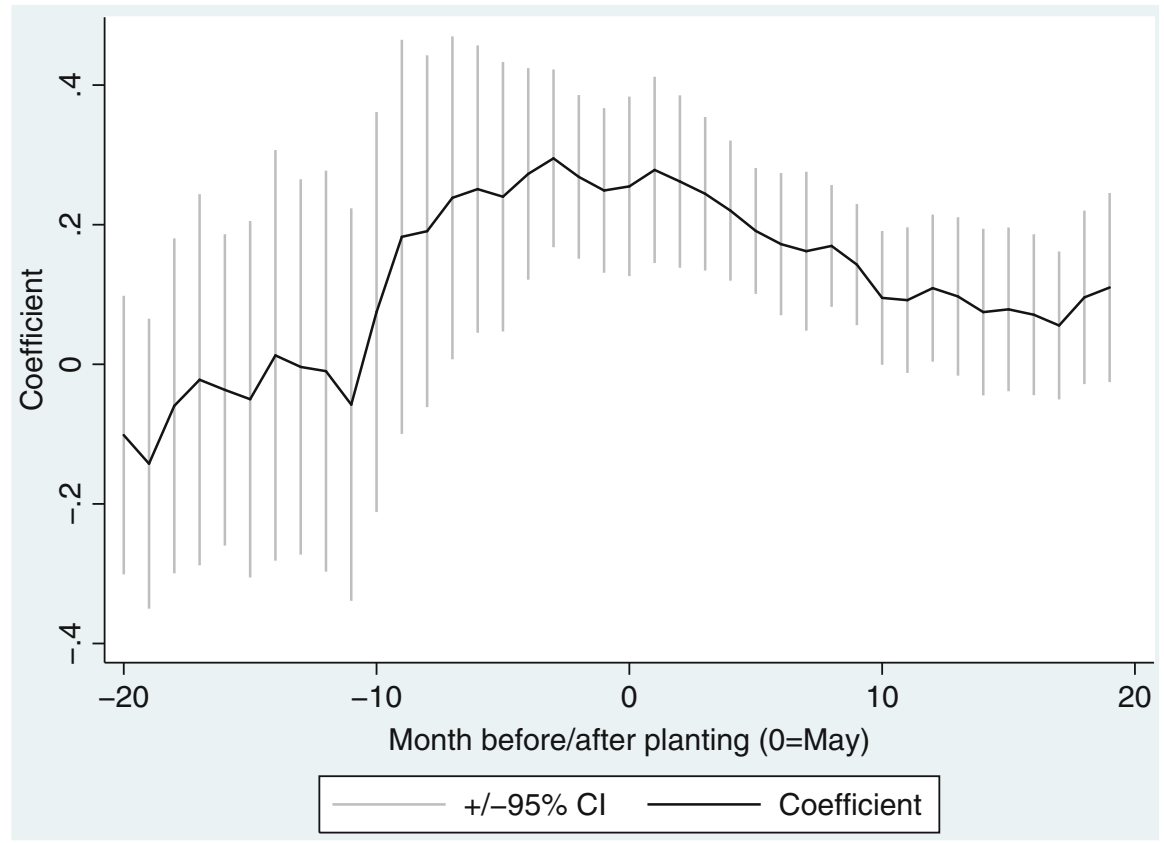

Fig. 18.1 Explanatory power of the wholesale prices over time for corn production 


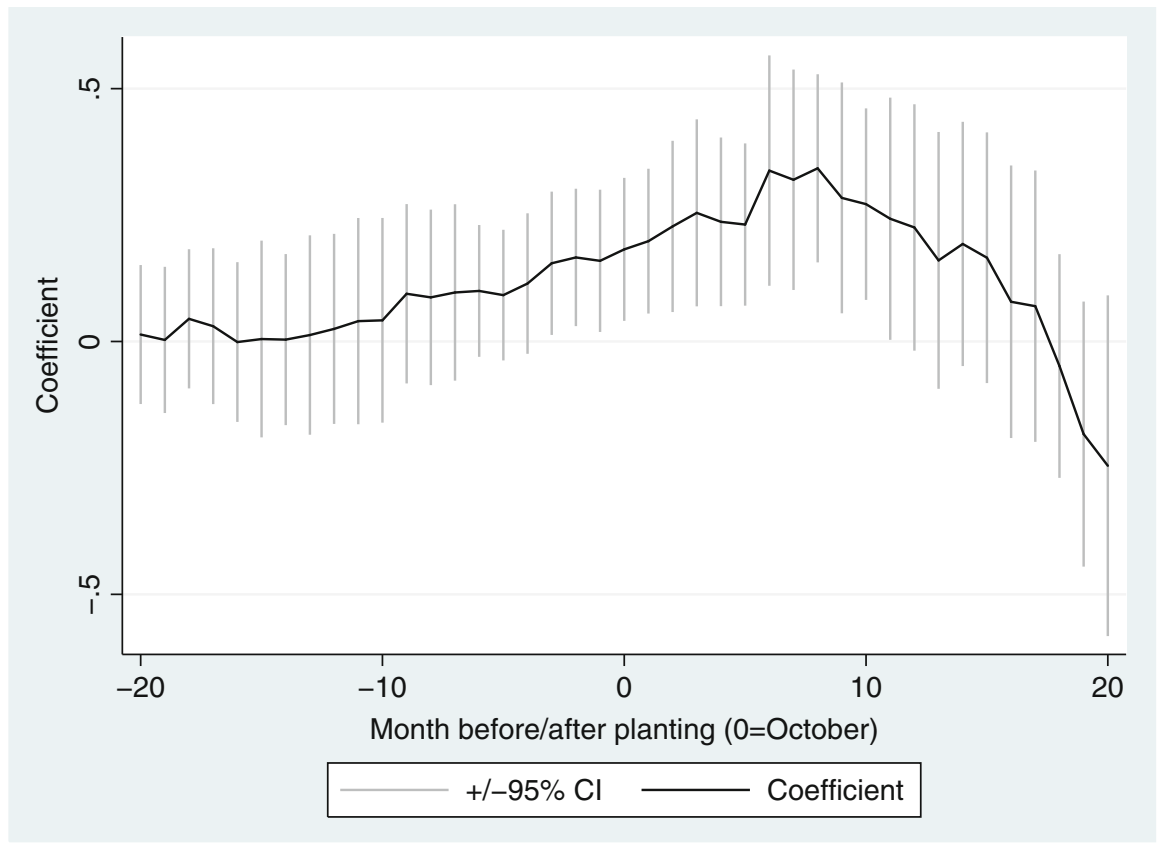

Fig. 18.2 Explanatory power of the wholesale prices over time for winter wheat production

Fig. 18.3 for indica rice. The figures show the coefficients and the $95 \%$ confidence intervals; the statistical significance of the response can be inferred from the figures. The further the distance between the bars and the $y=0$ line, the higher the level of significance. If the $y=0$ line is included in the bars, the coefficient is not statistically significant at the $5 \%$ level. The months before or after planting are depicted on the $x$-axis of the graphs.

Prices far before or after planting did not have much explanatory power for all crops; hence they do not influence production strongly. However, prices around planting time are usually highly significant and, at least for corn and rice, also have the highest coefficient. For rice, prices are significant in a few months far before planting, which may be attributed to the high level of autocorrelation. Nevertheless, both the level of significance and the coefficient increased and reached their highest level around planting time. Both rice and corn have a relatively short growing timeabout 2-6 months - compared to wheat. This explains why prices during planting period were very important as farmers chose their area and had only little time afterwards to influence yields. Particularly for rice, the beginning of the growing season is highly important and a lack of water cannot be compensated for at a later stage. The finding of a decreased level of significance and lower coefficients a few months after planting is therefore consistent with our expectations. For wheat, the graph looks different: the level of significance as well as the size of the coefficient increased even after planting and reached their highest levels around 6-8 months 


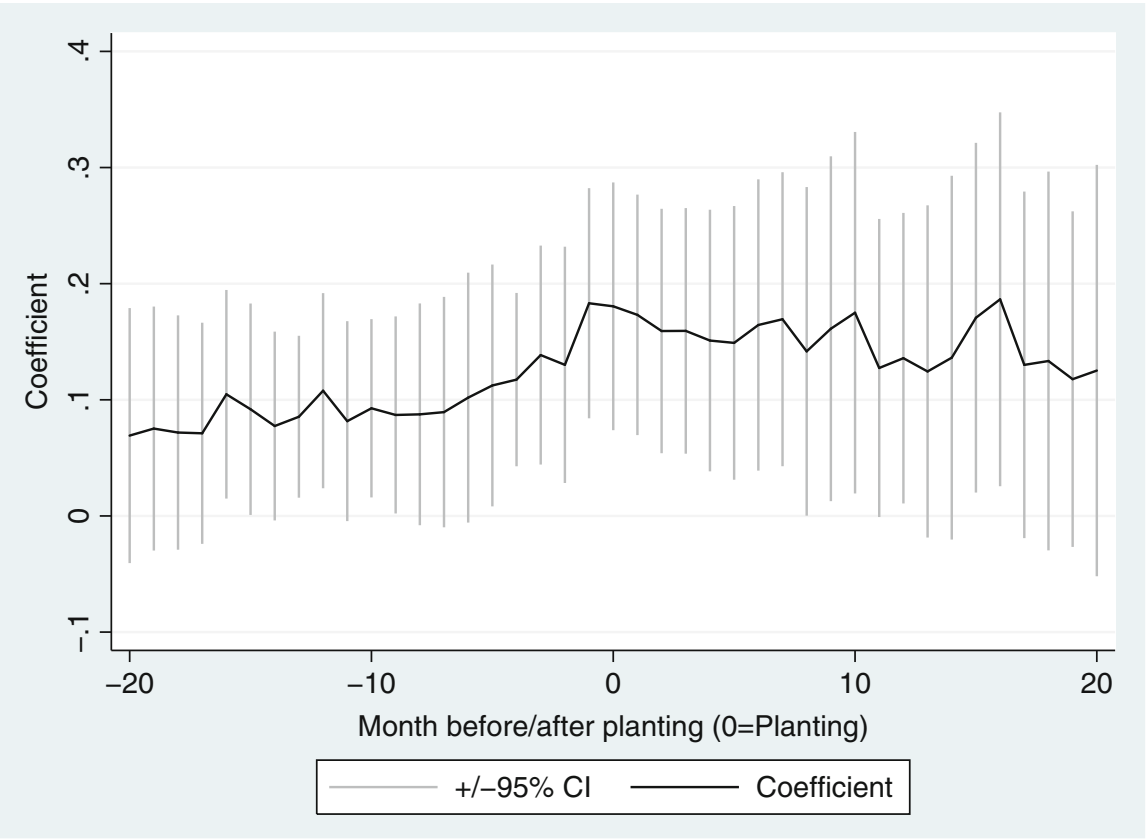

Fig. 18.3 Explanatory power of the wholesale prices over time for indica rice production

after planting. This can be explained by the different growing patterns, i.e., wheat grows for about 7-9 months after it is planted. Furthermore, the most sensitive phase of the crop is the flowering and yield formation period, whereby the wheat plant is very sensitive to water and temperatures (FAO 2015). This period is around 65-15 days before the harvest. As a result, it is crucial how farmers take care of their crops during this time period, while the establishment, tillering, and winter dormancy periods are of minor relevance (ibid.). Considering this, it matches our expectations that prices around 6 months after planting are very important for yield. For area however, prices at planting time should be the crucial factor. Although without making a distinction between area and yield, it is not possible to draw further conclusions about this.

Comparing the different crops, we found that farmers seem to react earlier to corn prices than the prices of winter wheat and indica rice. Rice showed the lowest response to prices, which might be a result of relatively high costs of area reallocation. For all crops, prices remained highly significant for a while after planting. This indicates that not only area but also yield respond to prices, regardless of whether it is due to fertilizer or pesticide application, irrigation, or other factors. For prices at harvesting time and thereafter, this method suffers from endogeneity problems as it is no longer clear if prices drive production or vice versa. Therefore, this method is only robust for the time before harvesting. 
A clear result of this analysis is that farmers, at least on average, do not mainly take into account previous year's planting or harvesting prices but rather consider current prices around planting time to be the more important. This is at odds with naïve and Nerlovian price expectation models, which use lagged harvest prices for estimating production decisions. Economically, it makes sense to use current prices as they include more information about the demand and supply situation than last year's prices.

Additional graphs which show the significance ( $p$-values) of the supply response over time for all crops and both estimators are shown in the appendix (Figs. 18.4 and 18.5). For these and the subsequent graphs, model specification two was used for all crops, and only the prices were varied over time while all other explanatory variables were kept the same. As expected, these graphs show a U-shaped curve with more or less distortions depending on the crop and estimator. Figures 18.6 and 18.7 show the same results for corn while also illustrating the results for other variables: Fig. 18.6 for the difference GMM estimator and Fig. 18.7 for the system GMM estimator. These graphs again support our hypothesis that the difference GMM estimator performs better than the system GMM estimator. The fluctuations of the system GMM results were much higher, particularly for winter wheat and indica rice as shown in Fig. 18.5. Furthermore, the fluctuations of the non-price variables were also much higher, as indicated in Fig. 18.7. In general, the period up to which prices are significant extended further after planting for the difference GMM, while in the case of winter wheat the period also started before planting.

This method of investigating prices at different points in time may also be used for general model specification tests. For a robust model, we expect the significance of the tested variables to consist of low-frequency components, which implies that there are only slow and smooth changes. The occurrence of big fluctuations in a specification, in particular if some variables constantly alternate between being insignificant and significant, suggest that the specification is not robust. Figure 18.5 and in particular Fig. 18.7 accordingly indicate that the system GMM specification is less consistent than the difference GMM specification. However, the system GMM fluctuations may still be acceptable; for problematic specifications, much higher fluctuations can easily be observed. Interestingly, prices around 2-5 months before planting time seem to have such a high explanatory power in the case of the system GMM that all other variables apart from the lagged production became insignificant (Fig. 18.7). This is an indication that prices before planting might be the most important factor influencing final production. Examining the area and yield response separately could shed more light on this issue. Overall, the price response and the response to other variables were consistent with our expectations, even though many variables turned out to be insignificant. 


\subsection{Conclusion}

The corn, winter wheat, and indica production response for the main agricultural provinces in China was analyzed using the difference GMM estimator and, for comparison, the system GMM estimator. The major findings include the following: (1) All crops strongly responded to prices at planting time. (2) The price response of corn and wheat was higher than rice. (3) While prices shortly before and after planting period had very high explanatory power, prices further away from planting period had lower coefficients and were mostly insignificant. (4) Wheat was an exception in the sense that its prices were highly significant long after planting and showed large coefficients, which could be attributed to wheat's long growing period and the crop's sensitivity 1-2 months before harvest. (5) High temperatures negatively influenced production for all crops, which may become problematic in the future due to climate change impacts. (6) Irrigation was measured poorly and therefore may have limited the significance of the results; nevertheless the results indicated that irrigation may partly help to mitigate a shortfall in rainfall but cannot (fully) compensate for the negative effects of high temperatures. (7) Fertilizer prices had a negative impact on corn production only.

In general, the difference GMM estimator seems to perform better than the system GMM estimator. The presented method to analyze the importance of prices at different points in time may also be used for general model specification tests if data on explanatory variables is available at a sufficiently high frequency.

The mixed evidence regarding the role of weather events and irrigation in affecting production could be due to the use of province-level data, which might be too aggregated to study spatially differentiated weather impacts. On the other hand, the panel data contained observations obtained over time, which is an important advantage over cross-sectional farm-level data, in particular when studying the role of determinants with little spatial dispersion (such as prices). The analysis of prices for production, one of the main contributions of this chapter, could only be undertaken with the help of a panel data set over multiple years. Not only do the findings indicate that farmers use up-to-date price information when making their production decisions, but the month-specific price elasticities also highlight when the Chinese agricultural sector can best respond to price spikes and scarcities. As the price elasticities ranged from $16 \%$ (rice) to $34 \%$ (wheat), increasing domestic demand can be met to a substantial extent by supply expansion - provided that prices are suitable signals about supply and demand conditions.

Acknowledgments The authors are grateful for the financial support of the Federal Ministry of Economic Cooperation and Development of Germany (BMZ) within the research project "Volatility in Commodity Markets, Trade Policy, and the Poor." The authors are also thankful for the financial support from the European Commission within the FoodSecure project and National Natural Science Foundation within research project "National Food Security Projection, Early Warning and Development Strategy" (71333013). Furthermore, the authors thank Tobias Heimann, Mahsa Shahbandeh, and Ling Zhu for collecting valuable data and providing research assistance and Mekbib Haile for very fruitful discussions on the modeling approach. 


\section{Appendix}

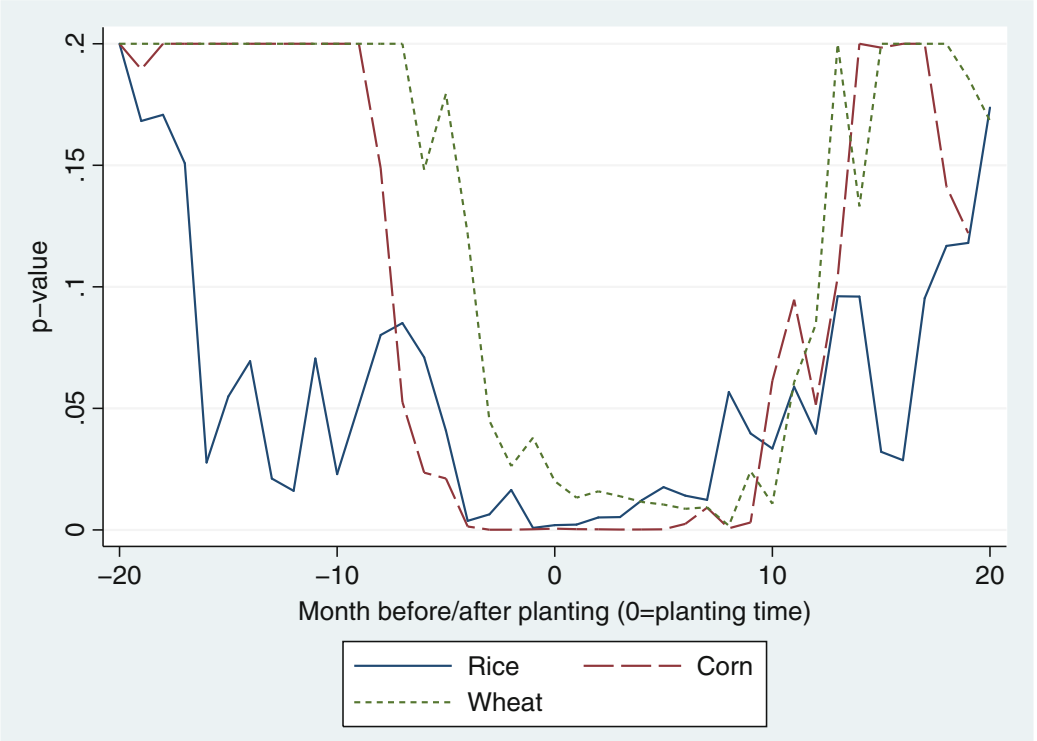

Fig. 18.4 Significance ( $p$-value) of the wholesale prices over time for the difference GMM estimator

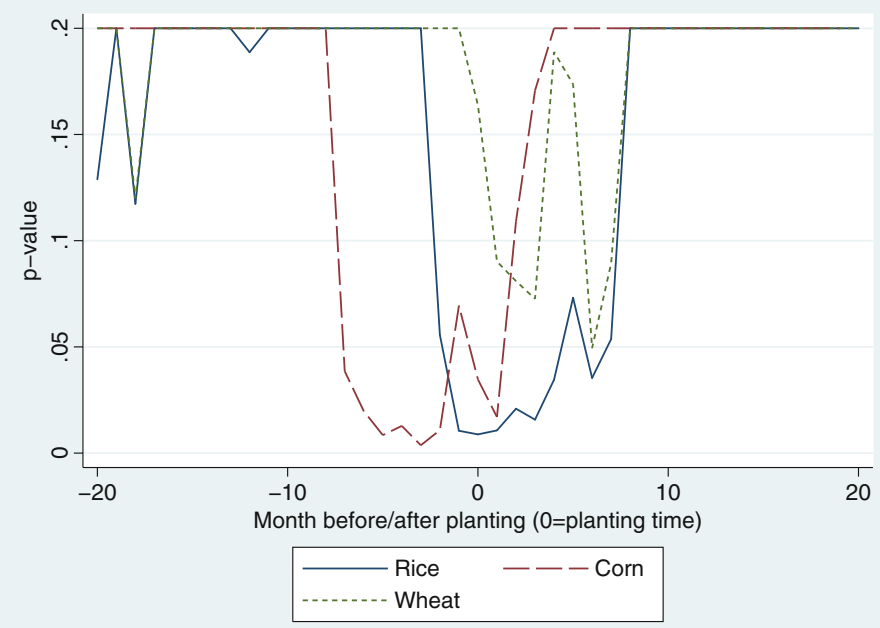

Fig. 18.5 Significance ( $p$-value) of the wholesale prices over time for the system GMM estimator 


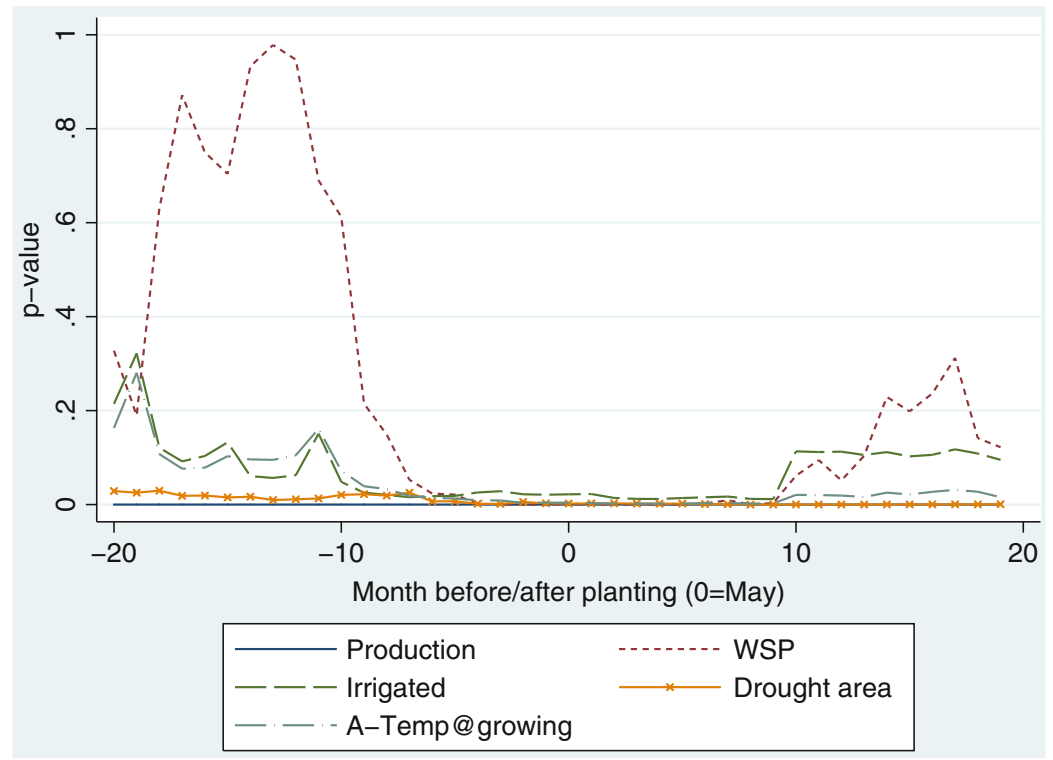

Fig. 18.6 Significance ( $p$-value) of the explanatory variables over time for the second corn regression using the difference GMM estimator. Not all explanatory variables are shown to maintain recognizability, and the prices are the only variables which were varied over time

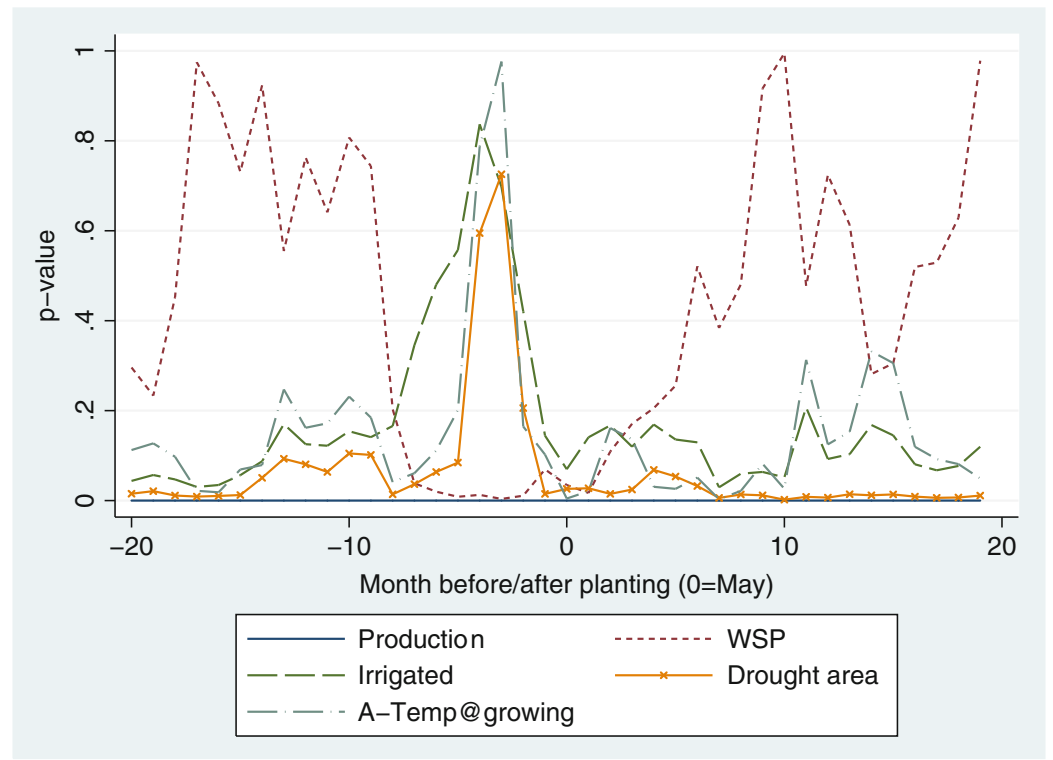

Fig. 18.7 Significance ( $p$-value) of the explanatory variables over time for the second corn regression using the system GMM estimator. Not all explanatory variables are shown to maintain recognizability, and the prices are the only variables which were varied over time 
Open Access This chapter is distributed under the terms of the Creative Commons AttributionNoncommercial 2.5 License (http://creativecommons.org/licenses/by-nc/2.5/) which permits any noncommercial use, distribution, and reproduction in any medium, provided the original author(s) and source are credited.

The images or other third party material in this chapter are included in the work's Creative Commons license, unless indicated otherwise in the credit line; if such material is not included in the work's Creative Commons license and the respective action is not permitted by statutory regulation, users will need to obtain permission from the license holder to duplicate, adapt or reproduce the material.

\section{References}

Arellano M, Bond S (1991) Some tests of specification for panel data: Monte Carlo evidence and an application to employment equations. Rev Econ Stud 58(2):277-297

Arellano M, Bover O (1995) Another look at the instrumental variable estimation of errorcomponents models. J Econometrics 68(1):29-51

Baum CF (2006) An introduction to modern econometrics using Stata. Stata, College Station, TX

Blundell R, Bond B (1998) Initial conditions and moment restrictions in dynamic panel data models. J Econometrics 87(1):115-143

Bond S (2002) Dynamic panel models: a guide to micro data methods and practice. Portuguese Econ J 1(2):141-162

Colman D (1983) A review of the arts of supply response analysis. Rev Market Agric Econ 51(3):201-230

de Brauw A, Huang J, Rozelle S (2004) The sequencing of reform policies in China's agricultural transition. Econ Transit 12(3):427-465

Efendic A, Pugh G, Adnett N (2009) Institutions and economic performance: system GMM modelling of institutional effects in transition. Unpublished paper, available at http://www. riinvestinstitute.org/pdf/Efendic_et_al.pdf.

FAO (2015) Wheat crop information. Available at http://www.fao.org/nr/water/cropinfo_wheat. html.

Ghatak S, Seale J (2001) Supply response and risk in Chinese agriculture. J Dev Stud 37(5):141150

Haile MG, Brockhaus J, Kalkuhl M (2015) Short-term acreage forecasting and supply elasticities for staple food commodities in major producer countries. Forthcoming

Haile MG, Kalkuhl M, von Braun J (2016) Worldwide acreage and yield response to international price change and volatility: a dynamic panel data analysis for wheat, rice, corn, and soybeans. Am J Agric Econ 98(1):172-190. Available at http://ajae.oxfordjournals.org/content/98/1/172

Holtz-Eakin D, Newey W, Rosen HS (1988) Estimating vector autoregressions with panel data. Econometrica 56(6):1371-1395

Huang J, Rozelle S (1996) Technological change: rediscovering the engine of productivity growth in China's rural economy. J Dev Econ 49:337-369

Huang J, Rozelle S (2006) The emergence of agricultural commodity markets in China. China Econ Rev 17(3):266-280

Huang J, Wang X, Zhi H, Huang Z, Rozelle S (2011) Subsidies and distortions in China's agriculture: evidence from producer-level data. Aust J Agric Resource Econ 55:53-71

Huang J, Wang X, Rozelle S (2013) The subsidization of farming households in China's agriculture. Food Policy 41:124-132

Lin JY (1991) The household responsibility system reform and the adoption of hybrid rice in China. J Dev Econ 36(2):353-372

Lin JY (1992) Rural reforms and agricultural growth in China. Am Econ Rev 82(1):34-51

Liu B, Keyzer M, van den Boom B, Zikhali P (2012) How connected are Chinese farmers to retail markets? New evidence of price transmission. China Econ Rev 23(1):34-46 
Roodman D (2009) How to do xtabond2: an introduction to difference and system GMM in Stata. Stata J 9(1):86-136

Tao F, Yokozawa M, Xu Y, Hayashi Y, Zhang Z (2006) Climate changes and trends in phenology and yields of field crops in China, 1981-2000. Agric Forest Meteorol 138(1-4):82-92

Wang J, Mendelsohn R, Dinar A, Huang J, Rozelle S, Zhang L (2009) The impact of climate change on China's agriculture. Agric Econ 40(3):323-337

Windmeijer F (2005) A finite sample correction for the variance of linear efficient two-step GMM estimators. J Econometrics 126(1):25-51

Yu W, Jensen HG (2010) China's agricultural policy transition: impacts of recent reforms and future scenarios. J Agric Econ 61(2):343-368

Yu B, Liu F, You L (2011) Dynamic agricultural supply response under economic transformation: a case study of Henan, China. Am J Agric Econ 94(2):370-376 